\title{
SEVERIDADE DA MANCHA-MARROM EM TRIGO CULTIVADO COM DIFERENTES FORMAS DE NITROGÊNIO E DOSES DE MANGANÊS ${ }^{(1)}$
}

\author{
Luiz Antônio Zanão Júnior ${ }^{(2)}$, Paulo Henrique Moreira Coelho ${ }^{(3)}$, \\ Renildes Lúcio Ferreira Fontes ${ }^{(4)}$, Vinícius Tavares de Ávila ${ }^{(3)}$ \& \\ Igor Ken Kawamura ${ }^{(3)}$
}

\begin{abstract}
RESUMO
A fonte de $\mathbf{N}$ fornecido às culturas influencia algumas propriedades do solo como o pH, causando efeitos indiretos na disponibilidade e, consequentemente na absorção de nutrientes pela planta. Em relação ao Mn, que pode influenciar na susceptibilidade de plantas a doenças, pode haver alterações até mesmo nas relações patógeno-hospedeiro. O objetivo deste trabalho foi avaliar o efeito de duas fontes de $\mathrm{N}$ e cinco doses de $\mathrm{Mn}$ na severidade da mancha-marrom em plantas de trigo, bem como na produção de matéria seca da parte aérea e raízes, a absorção desses nutrientes pelas plantas e a disponibilidade do Mn no solo. $\mathrm{O}$ experimento foi instalado em casa de vegetação e os tratamentos dispostos em um esquema fatorial $(2 \times 5)$, sendo duas fontes de $\mathrm{N}$ (amoniacal e nítrica) e cinco doses de Mn (0; 2,$5 ; 5,0 ; 10,0$ e $20,0 \mathrm{mg} \mathrm{dm}^{-3}$ ), em delineamento de blocos casualizados, com quatro repetições. Foram utilizadas amostras de um Latossolo Vermelho distrófico em vasos contendo $2,2 \mathrm{dm}^{3}$, com três plantas de trigo. Aos 45 dias após emergência (DAE), as plantas foram inoculadas com uma suspensão de $10^{5} \mathrm{~mL}^{-1}$ conídios de Bipolaris sorokiniana. Foram determinados o grau de severidade final da manchamarrom, a produção de matéria seca da parte aérea e das raízes, e os teores foliares de $\mathrm{N}$ e Mn nas plantas de trigo, assim como a disponibilidade de Mn no solo. Verificou-se efeito das fontes de $\mathrm{N}$ e das doses de $\mathrm{Mn}$ apenas na severidade da mancha-marrom e nos teores de Mn no solo e nas folhas. Houve respostas quadráticas para os teores de Mn no solo e nas folhas e para a severidade da mancha-
\end{abstract}

\footnotetext{
(1) Recebido para publicação em agosto de 2008 e aprovado em julho de 2009 .

(2) Pesquisador do Instituto Agronômico do Paraná - IAPAR. Pólo Regional de Pesquisa de Ponta Grossa, Caixa Postal 129, CEP 84001-970 Ponta Grossa (PR). Bolsista do CNPq. E-mail: lzanao@iapar.br

(3) Graduandos em Agronomia, Universidade Federal de Viçosa - UFV. Av PH Rolfs s/n, CEP 36570-000 Viçosa (MG). E-mails: phmoreiracoelho@yahoo.com.br; vtasolosufv@yahoo.com.br; igor210983@hotmail.com

(4) Professor Associado do Departamento de Solos, UFV. Bolsista do CNPq. E-mail: renildes@ufv.br
} 
marrom no trigo. A fonte amoniacal $\left[\left(\mathrm{NH}_{4}\right)_{2} \mathrm{SO}_{4}\right]$ proporcionou maior disponibilidade do $\mathrm{Mn}$ no solo do que a fonte nítrica $\left[\mathrm{Ca}\left(\mathrm{NO}_{3}\right)_{2}\right]$, que foi acompanhada de aumento do teor foliar de Mn na planta e de diminuição da severidade da mancha-marron em trigo.

Termos de indexação: Triticum aestivum L., Bipolaris sorokiniana, nutrição mineral.

\title{
SUMMARY: SEVERITY OF SPOT BLOTCH IN WHEAT CULTIVATED WITH DIFFERENT FORMS OF NITROGEN AND MANGANESE DOSES
}

\begin{abstract}
The nitrogen source applied to crops may alter some soil properties such as $p H$, resulting in changes in the soil nutrient availability and plant nutrient uptake. Manganese (Mn), which can influence the plant susceptibility to diseases, may even affect host-pathogen relationships. The objective of this study was to evaluate the effect of soil application of two $N$ sources and five Mn doses on the severity of the wheat spot blotch disease. Additionally, shoot and root dry matter production, plant Mn uptake and soil Mn availability were evaluated. An experiment in a randomized block design was carried out in a greenhouse, in a $2 \times 5$ factorial scheme with two $\mathrm{N}$ sources [ $\left(\mathrm{NH}_{4}\right)_{2} \mathrm{SO}_{4}$ and $\left.\mathrm{Ca}\left(\mathrm{NO}_{3}\right)_{2}\right]$ and five Mn doses (0; 2.5; 5.0; 10.0 and $\left.20.0 \mathrm{mg} \mathrm{dm}^{-3}\right)$ with four replications. Plants were grown in a dystrophic Red Latosol (Oxisol), in $2.2 \mathrm{dm}^{3}$ plastic pots, with three wheat plants per pot. Forty-five days after emergence (DAE) the plants were inoculated with a Bipolaris sorokiniana suspension containing $10^{5}$ conidial fungi per $m L$. The disease severity degree, shoot and root dry matter production, and the Nand Mn leaf contents in the wheat plants were determined, as well as the soil Mn availability. The $N$ sources and Mn doses affected only the disease severity degree, soil available Mn and leaf Mn. Quadratic responses were found for the contents of soil $M n$, leaf $M n$ and disease severity degree as a function of the increased $\mathrm{Mn}\left(\mathrm{MnCl}_{2} \cdot 4 \mathrm{H}_{2} \mathrm{O}\right)$ rates applied to soil. The ammonium-based source $\left[\left(\mathrm{NH}_{4}\right)_{2} \mathrm{SO}_{4}\right.$ ] resulted in a greater Mn availability than the nitric-based source [Ca $\left(\mathrm{NO}_{3}\right)_{2}$, which was followed by an increase in foliar Mn and a drop in the severity degree of wheat spot blotch.
\end{abstract}

Index terms: Triticum aestivum L., Bipolaris sorokiniana, mineral nutrition.

\section{INTRODUÇÃO}

O trigo (Triticum aestivum L.) é um dos cereais mais consumidos no mundo, juntamente com o arroz e o milho. O Brasil é um país importador desse cereal, e a produção brasileira ocupa o segundo lugar na América do Sul, após a Argentina, sendo os estados do Paraná e Rio Grande do Sul os principais produtores (AGRIANUAL, 2008). Em razão desta produção insuficiente para a demanda do mercado interno brasileiro, estudos visando elevar a produtividade nacional são necessários, incluindo aqueles envolvendo a nutrição e fertilização desta cultura.

$\mathrm{O} \mathrm{N}$ é o nutriente mais exigido pela maioria das culturas para uma produção satisfatória, pois está envolvido no desenvolvimento de funções metabólicas essenciais, tais como a síntese proteica e a fotossíntese (Marschner, 1995). Pelo fato de o trigo não realizar fixação biológica do $\mathrm{N}$, praticamente esse nutriente vem do solo e dos fertilizantes. A adubação nitrogenada nesta cultura tem sido fundamental no aumento da produção e da qualidade de grãos (Hussain et al., 1996).
As plantas geralmente absorvem o $\mathrm{N}$ mineral em duas formas, amoniacal $\left(\mathrm{NH}_{4}{ }^{+}\right)$e nítrica $\left(\mathrm{NO}_{3}{ }^{-}\right)$ (Pilbeam \& Kirkby, 1992). A fonte de $\mathrm{N}$ da adubação influencia o $\mathrm{pH}$ do solo e da rizosfera (Römheld, 1986), variando a absorção com a espécie, o estado nutricional da planta e a capacidade tampão do solo (Marschner, 1995). Os fertilizantes nitrogenados amoniacais tendem a acidificar o solo pelo processo de nitrificação. Em revisão sobre a adubação nitrogenada no Brasil, Peres \& Suhet (1986) encontraram diferentes respostas do trigo ao $\mathrm{N}$ devido às variações na fertilidade do solo, no clima, nos cultivares e nas práticas culturais, incluindo a fonte deste nutriente.

$\mathrm{O}$ estado nutricional da planta reflete em seu comportamento diante de um patógeno. Segundo Agrios (1980), a forma do $\mathrm{N}$ disponível para a planta e para o patógeno influencia a severidade da doença mais que a quantidade fornecida desse elemento. Vários autores afirmam que a fonte de $\mathrm{N}$ pode causar maior ou menor severidade das doenças, dependendo, entre outros fatores, do patossistema (Huber \& Thompson, 2007). A fertilização nitrogenada amoniacal, por 
exemplo, apresenta efeitos adversos em patógenos como Pythium, Diplodia, Phymatotrichum, Streptomyces, Phialophora, Verticillium, Pseudomonas, Puccinia e Colletotrichum (Huber \& Watson, 1974) e de maneira geral a nítrica em Fusarium e Rhizoctonia (Huber, 1989).

A forma em que o Mn predomina no solo está diretamente relacionada com seu $\mathrm{pH}$, sendo sua disponibilidade aumentada com o decréscimo do $\mathrm{pH}$ do solo (Borkert, 1993). Dessa forma, fatores que provocam o decréscimo do $\mathrm{pH}$ do solo, como fertilizantes nitrogenados amoniacais, podem aumentar a disponibilidade deste micronutriente para as plantas e, consequentemente, sua absorção. O Mn é um micronutriente que desempenha funções importantes na planta, como cofator e ativador enzimático, necessário na fotossíntese e síntese proteica. Além disso, atua no metabolismo do $\mathrm{N}$ e nos compostos cíclicos e como precursor de aminoácidos e hormônios (El-Jaoual \& Cox, 1998). Ele atua como ativador da enzima fenilalanina amônio liase (PAL), que desencadeia reações levando à produção de vários compostos fenólicos (Hammerschmidt, 1999) e posteriormente participa como cofator da enzima peroxidase, associada à polimerização de álcoois para a formação da lignina no final da rota do ácido chiquímico (Leina et al., 1996). Esses compostos estão relacionados à maior resistência das plantas aos patógenos (Thompson \& Huber, 2007).

A literatura registra o $\mathrm{Mn}$ reduzindo a severidade de doenças como podridão das raízes, mal-do-pé, míldio pulverulento, ferrugem da folha e do colmo dos cereais, tombamento e murcha vascular do algodoeiro, requeima e sarna da batata inglesa, manchas foliares em soja e vassoura-de-bruxa do cacaueiro (Aguilar, 1999; Thompson \& Huber, 2007). Na cultura do trigo, foram registrados casos de redução da incidência do mal-do-pé e do míldio pulverulento com a aplicação do Mn (Hill et al., 1999; Heckman et al., 2003).

Assim, a fonte de $\mathrm{N}$ e maior disponibilidade de $\mathrm{Mn}$ no solo estariam relacionadas com o aumento da resistência das plantas às doenças. Desse modo, o objetivo deste trabalho foi avaliar o efeito de fontes de $\mathrm{N}$ e doses de $\mathrm{Mn}$ na severidade da mancha-marrom em plantas de trigo, bem como na produção de matéria seca da parte aérea e raízes, teores foliares desses nutrientes nestas plantas, bem como na disponibilidade do Mn no solo.

\section{MATERIAL E MÉTODOS}

O experimento foi instalado em casa de vegetação, do Departamento de Solos da Universidade Federal de Viçosa, MG. Os tratamentos foram dispostos em um esquema fatorial $(2 \times 5)$, sendo duas fontes de $\mathrm{N}$, amoniacal $\left[\left(\mathrm{NH}_{4}\right)_{2} \mathrm{SO}_{4}\right]$ e nítrica $\left[\mathrm{Ca}\left(\mathrm{NO}_{3}\right)_{2}\right]$ e cinco doses de Mn $\left(0 ; 2,5 ; 5,0 ; 10,0\right.$ e $\left.20,0 \mathrm{mg} \mathrm{dm}^{-3}\right)$, em delineamento em blocos casualizados, com quatro repetições. As quantidades de Ca e $\mathrm{S}$ fornecidas pelas fontes utilizadas foram balanceadas para todos os tratamentos, utilizando-se $\mathrm{CaCl}_{2}, \mathrm{CaSO}_{4}, \mathrm{KCl}$ e $\mathrm{K}_{2} \mathrm{SO}_{4}$.

Foram utilizadas amostras de um Latossolo Vermelho distrófico, coletado em Três Marias, (MG), possuindo $180 \mathrm{~g} \mathrm{~kg}^{-1}$ de argila, com $\mathrm{pH} \mathrm{H} \mathrm{H}_{2} \mathrm{O}(1: 2,5)=$ 4,90; P (Mehlich-1) = 0,3 mg dm${ }^{-3}$; P-rem $=33,3 \mathrm{mg} \mathrm{L}^{-1}$; $\mathrm{K}\left(\right.$ Mehlich-1) $=6,0 \mathrm{mg} \mathrm{dm}{ }^{-3} ; \mathrm{Al}^{3+}, \mathrm{Ca}^{2+}, \mathrm{Mg}^{2+}, \mathrm{H}+\mathrm{Al}$, $=0,25 ; 0,07 ; 0,01$ e $3,0 \mathrm{cmol}_{\mathrm{c}} \mathrm{dm}^{-3}$, respectivamente; saturação por bases $=3,22 \%$, matéria orgânica $=$ 0,9 dag kg-1 $;$ B (água quente), $\mathrm{Cu}, \mathrm{Fe}$ e Mn (Mehlich1) $=0,32 ; 0,06 ; 33,5$ e $5 \mathrm{mg} \mathrm{dm}^{-3}$, respectivamente e com capacidade de campo de $0,135 \mathrm{~kg} \mathrm{~kg}^{-1}$ e densidade de $1,02 \mathrm{~kg} \mathrm{dm}^{-3}$.

A unidade experimental consistiu de vasos de $2,5 \mathrm{dm}^{3}$, contendo $2,2 \mathrm{dm}^{3}$ de solo, com três plantas de trigo (cv. BR18). Inicialmente, o solo foi pesado e colocado em sacos plásticos com capacidade para $5 \mathrm{dm}^{3}$, para a realização da correção da acidez do solo. Como corretivo da acidez, foi utilizada uma mistura de $\mathrm{CaCO}_{3}+\mathrm{MgCO}_{3}$ na proporção de 3:1 para elevar a saturação por bases do solo para $50 \%$. Após a homogeneização do solo com o corretivo, foi adicionada água deionizada, para elevar a umidade a $80 \%$ da capacidade de campo, com posterior período de incubação de 30 dias.

Após o período de incubação, foram adicionados $400 \mathrm{mg} \mathrm{dm}^{-3}$ de $\mathrm{P}\left(\mathrm{CaHPO}_{4}\right)$ e as respectivas doses de $\mathrm{Mn}$, utilizando-se como fonte o $\mathrm{MnCl}_{2} \cdot 4 \mathrm{H}_{2} \mathrm{O}$. A aplicação foi feita em todo o solo e a semeadura foi realizada a $1 \mathrm{~cm}$ de profundidade, distribuindo-se oito sementes por vaso.

O desbaste foi realizado aos cinco dias após a emergência (DAE), deixando-se três plantas por vaso. Nessa ocasião, foi realizada a primeira aplicação de N e micronutrientes e a dose total de K e S. A segunda e a terceira parcelas da adubação nitrogenada e micronutrientes foram realizadas, respectivamente, aos 15 e 30 DAE. As adubações foram realizadas através de soluções nutritivas. A umidade do solo no vaso foi mantida em torno de $80 \%$ da capacidade de campo, utilizando água deionizada. A quantidade total dos nutrientes aplicados nas adubações, em $\mathrm{mg} \mathrm{kg}^{-1}$, foi: $\mathrm{N}, 160 ; \mathrm{K}, 210 ; \mathrm{S}, 60 ; \mathrm{Mg}, 60 ; \mathrm{B}, 1 ; \mathrm{Cu}, 1,5 ; \mathrm{Fe}, 2$; Mo, 0,2 e Zn, 5 .

Aos $45 \mathrm{DAE}$, as folhas de uma planta em cada vaso foram colhidas, secas em estufa de circulação forçada de ar, a $65^{\circ} \mathrm{C}$, durante $72 \mathrm{~h}$ e moídas em moinho tipo Willey, em peneira de malha $0,84 \mathrm{~mm}$. Foram determinados os teores de $\mathrm{N}$ pelo método Kjeldahl e de Mn por espectrofotometria de absorção atômica após digestão nítrico-perclórica.

As plantas foram transferidas para câmara de inoculação e inoculadas com o fungo Bipolaris sorokiniana (Sacc.) Shoem, na concentração de $10^{5}$ conídios por mL. A suspensão de inóculo foi preparada adicionando-se $10 \mathrm{~mL}$ de água destilada estéril em cada 
placa com o isolado, fazendo-se uma raspagem superficial com espátula para liberação dos conídios. A suspensão foi filtrada em gaze para eliminação de fragmentos de micélio e meio de cultura. Após a filtragem, a suspensão de conídios foi ajustada para a concentração desejada.

A inoculação das plantas foi realizada pulverizandoas com a suspensão de conídios, com o auxílio de um atomizador manual (D. Vilbiss $\mathrm{n}^{\circ}$. 15). Imediatamente após a inoculação, as plantas foram transferidas para câmara de nevoeiro. Na câmara, a temperatura e a umidade relativa foram fixadas em $25 \pm 2{ }^{\circ} \mathrm{C}$ e $95 \pm 2 \%$, respectivamente, com nebulizadores funcionando por 40 segundos, a cada 30 minutos, durante $12 \mathrm{~h}$ e fotoperíodo contínuo de $12 \mathrm{~h}$, permanecendo assim por $24 \mathrm{~h}$. Em seguida, as plantas foram transferidas para câmaras de crescimento, com temperatura de $22 \pm 2{ }^{\circ} \mathrm{C}$, até os cinco dias após a inoculação. Nessa ocasião, foi avaliada a severidade da mancha-marrom. Empregou-se para tal a escala de Horsfall \& Barrat (1945), de 0 a $100 \%$ de severidade, considerando a área foliar doente.

Após avaliação da severidade da mancha-marrom, a parte aérea das plantas foi cortada. As raízes foram separadas do solo e lavadas. Posteriormente, ambas foram submetidas à secagem em estufa de circulação forçada de ar, a $65^{\circ} \mathrm{C}$, até massa constante.

Foram retiradas amostras de solo de $0,2 \mathrm{dm}^{3} \mathrm{em}$ cada unidade experimental, para determinação dos teores disponíveis de Mn (Mehlich-1).

O experimento foi repetido duas vezes e os dados de cada variável foram agrupados devido à homogeneidade da variância confirmada pelo teste de Cochran (Gomez \& Gomez, 1994). Os dados foram submetidos à análise de variância e ajustadas equações de regressão para o efeito das doses de Mn.

\section{RESULTADOS E DISCUSSÃO}

A severidade da mancha-marrom do trigo foi menor em plantas que receberam adubação nitrogenada amoniacal (Quadro 1). De forma semelhante, adicionando ao solo sulfato de amônio (mesma fonte nitrogenada deste trabalho), Smiley \& Cook (1973) observaram diminuição da severidade do mal-do-pédo-trigo. A diminuição ou aumento da severidade das doenças das plantas em função da fonte de $\mathrm{N}$ geralmente deve-se a mudanças no $\mathrm{pH}$ do solo ou da rizosfera (Keinath \& Loria, 1989). Como o sulfato de amônio tem reação ácida no solo, isso favorece maior disponibilidade de Mn para as plantas, possibilitando maiores teores foliares de $\mathrm{Mn}$, o que pode ter contribuído para a diminuição na severidade da doença.

Esta redução da severidade da mancha-marrom do trigo pode estar relacionada com o papel do Mn na biossíntese de compostos fenólicos e lignina e à importância da lignificação das paredes celulares como mecanismo de defesa contra patógenos (Marschner, 1995; Hill et al., 1999). Plantas de Agrotis sp. com deficiência de Mn apresentaram maior susceptibilidade ao mal-do-pé conforme verificado por Hill et al. (1999). Brown et al. (1984) verificaram que plantas de trigo com deficiência deste micronutriente apresentaram menores teores de compostos fenólicos solúveis e lignina na parte aérea. Isso reforça a importância da lignificação das paredes celulares na defesa das plantas aos patógenos e a relação entre este processo e o suprimento de Mn.

Assim como a deficiência de Mn, o excesso deste micronutriente também pode predispor as plantas a certas doenças (El-Jaoual \& Cox, 1998; Thompson \& Huber, 2007). Essa possibilidade ficou evidente neste trabalho, com elevados graus de severidade da manchamarrom (acima de $82 \%$ ), próximo à dose zero e à dose de $20 \mathrm{mg} \mathrm{dm}^{-3}$ de $\mathrm{Mn}$ adicionados ao solo, com diminuição da severidade (para cerca de 78 \%) com a dose $10 \mathrm{mg} \mathrm{dm}^{-3}$ (Figura 1). Esse efeito é evidenciado pela resposta quadrática da severidade da manchamarrom às doses de $\mathrm{Mn}$ adicionadas (Figura 1), observando-se que a severidade foi maior nas plantas crescidas em solos que receberam as maiores e as menores doses de Mn.

Resultados semelhantes foram encontrados por Aguilar (1999) em cacaueiro inoculado com o fungo Crinipelis perniciosa, agente causal da vassoura-debruxa e por Zanão Júnior et al. (2009) em plantas de

Quadro 1. Severidade da mancha-marrom (SEVMM), produção de matéria seca da parte aérea (MSPA), raízes (MSR), teores de $\mathrm{N}$ (TFN) e Mn (TFMn) em folhas de trigo e teores de Mn no solo (Mn Solo) adubado com duas fontes de $\mathrm{N}$

\begin{tabular}{lccccccc}
\hline \multirow{2}{*}{ Fonte } & SEVMM & MSPA & MSR & TFN & TFMn & Mn Solo \\
\hline & $\%$ & & & & g kg-1 & $\mathrm{mg} \mathrm{kg}^{-1}$ & $\mathrm{mg} \mathrm{dm}^{-3}$ \\
Amoniacal & $78,13 \mathrm{~b}$ & $2,51 \mathrm{a}$ & $1,06 \mathrm{a}$ & & $30,91 \mathrm{a}$ & $107,89 \mathrm{a}$ & $20,24 \mathrm{a}$ \\
Nítrica & $81,93 \mathrm{a}$ & $2,83 \mathrm{a}$ & $1,08 \mathrm{a}$ & $30,11 \mathrm{a}$ & $82,98 \mathrm{~b}$ & $17,16 \mathrm{~b}$ \\
CV (\%) & 7,06 & 18,74 & 43,37 & 5,05 & 6,93 & 21,65 \\
\hline
\end{tabular}

Médias (respostas às doses de Mn) seguidas de letras distintas, nas colunas, diferem significativamente entre si pelo teste de $\mathrm{F}$ $(\mathrm{p}<0,05)$. 

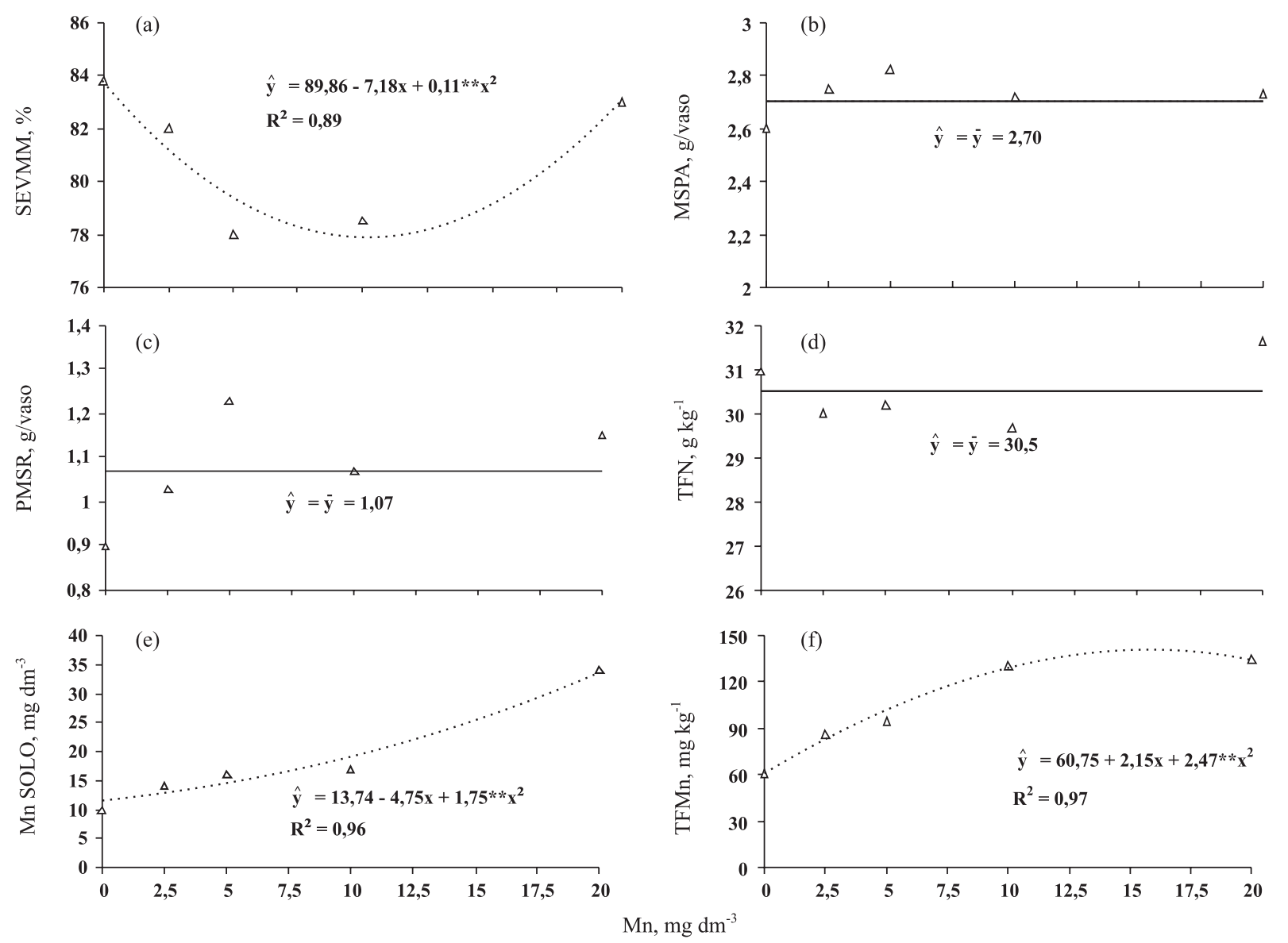

Figura 1. Severidade da mancha-marrom (a); produção de matéria seca da parte aérea (b); produção de matéria seca de raízes (c); teores de $\mathrm{N}$ em folhas de trigo (d); teores de Mn no solo (e); e teores de Mn em folhas de trigo (f), em plantas cultivadas em solos que receberam doses de Mn $(0 ; 2,5 ; 5,0 ; 10,0$ e $20,0 \mathrm{mg} \mathrm{dm}^{-3}$ ). **: significativo a $1 \%$ pelo teste de $\mathrm{t}$.

arroz inoculadas com Bypolaris oryzae, causador da mancha-parda. Reis et al. (1982) também verificaram maior severidade do mal-do-pé-do-trigo (Gaeumannomyces graminis) após a aplicação de calcário, que elevou o pH do solo causando deficiência de Mn, assim como dos outros micronutrientes catiônicos. Já em plantas com níveis elevados de Mn, foi verificada a oxidação do próprio Mn e de compostos fenólicos (Fecht-Christoffers et al., 2003), o que pode resultar em efeito negativo na rota do ácido chiquímico, resultando menor produção de compostos fenólicos e lignina, o que também pode ter ocorrido neste trabalho. Aguilar (1999) verificou que 2,5 $\mu \mathrm{mol} \mathrm{L}^{-1}$ de $\mathrm{Mn}$ na solução nutritiva reduziram a porcentagem de plantas de cacau infectadas pelo fungo Crinipelis perniciosa, causador da vassoura-de-bruxa, em comparação aos tratamentos com ausência de Mn e com a dose máxima utilizada $\left(20 \mu \mathrm{mol} \mathrm{L}{ }^{-1}\right)$. Zanão Júnior (2007) também verificou redução no acúmulo de lignina em plantas de arroz inoculadas com Bipolaris oryzae na maior dose de $\mathrm{Mn}$ utilizada $\left(10 \mu \mathrm{mol} \mathrm{L}^{-1}\right)$. A lignina é importante na resistência das plantas aos patógenos. Segundo Nicholson \& Hammerschmidt (1992), ela dificulta a penetração do fungo por ser formada de polímeros fenólicos resistentes à degradação enzimática. Além do mais, com o aumento da dose de Mn pode ocorrer aumento na atividade de enzimas como a peroxidase e a polifenoloxidase (Morgan et al., 1976). A peroxidase em algumas espécies vegetais pode oxidar compostos fenólicos na parede celular se a dose de Mn for excessiva (Wissemeier \& Horst, 1992). Com base nessas observações é de se esperar que a suscetibilidade do trigo à mancha-marrom aumente tanto na deficiência quanto na presença de teores elevados de $\mathrm{Mn}$. Os resultados deste trabalho corroboram essas observações que são indicativas de que o Mn deve estar na planta em quantidades adequadas para que ocorra maior resistência da planta hospedeira a patógenos.

Verificou-se efeito significativo da fonte de $\mathrm{N}$ nos teores de Mn no solo e nas folhas. A fonte amoniacal proporcionou maior disponibilidade do Mn no solo, que foi acompanhada de maior absorção deste micronutriente pela planta. No entanto, esta maior absorção não refletiu em maior produção de matéria seca de parte aérea e raízes, que não apresentaram diferença significativa em função da fonte de $\mathrm{N}$ utilizada (Quadro 1). 
He et al. (1999), aplicando $112 \mathrm{~kg} \mathrm{ha}^{-1} \mathrm{ano}^{-1}$ de $\mathrm{N}$ na forma amoniacal $\left(\mathrm{N}^{-} \mathrm{NH}_{4}{ }^{+}\right)$em quatro anos consecutivos, num pomar de Citrus paradisi, obsevaram decréscimo no $\mathrm{pH}$ do solo estudado em até 1,7 unidade. Por sua vez, menor $\mathrm{pH}$ verificado neste trabalho aumentou a disponibilidade de $\mathrm{Mn}$, que foi absorvido pela planta, aumentando os teores foliares deste micronutriente nas plantas que receberam a aplicação da fonte amoniacal (sulfato de amônio) (Quadro 1). Silva et al. (2003), avaliando o efeito de doses de N (uréia) e K durante três ciclos de produção da bananeira, observaram que o teor de $\mathrm{Mn}$ nas folhas aumentou para níveis acima do adequado, com queda na produção no $2^{\circ}$ e $3^{\circ}$ ciclos, possivelmente pela acidificação do solo que a uréia causou.

No que diz respeito à produção de matéria seca da parte aérea e raízes e teores de $\mathrm{N}$, não foram verificados aumentos devidos à fonte nitrogenada aplicada. Isso pode ter ocorrido pelo fato da dose de $\mathrm{N}$ aplicada, $150 \mathrm{mg} \mathrm{dm}^{-3}$, ter sido suficiente. A aplicação parcelada das fontes nitrogenadas no vaso, via solução nutritiva, praticamente em todo o volume de solo, aliada a condições adequadas de regime hídrico do solo, pode ter maximizado a utilização do $\mathrm{N}$ pelas plantas, não refletindo em diferenças em produção de biomassa e teor foliar de N (Quadro 1).

A maior disponibilidade do Mn no solo ocorreu provavelmente pela acidificação da rizosfera e do solo devido à fonte amoniacal. Após a absorção de um excesso de cátions, como a forma $\mathrm{NH}_{4}{ }^{+}$, as células restabelecem o equilíbrio eletroquímico aumentando a extrusão de $\mathrm{H}^{+}$(Marschner, 1995), ocorrendo a acidificação da rizosfera. $\mathrm{O}$ processo de nitrificação que ocorre após a aplicação da uréia também acidifica o solo. Esse fato também foi comprovado por Zanão Júnior et al. (2005), que observaram maiores teores de Mn e Zn tanto no solo quanto nas folhas de couveda-malásia, aliado a um $\mathrm{pH}$ em água do solo próximo às raízes menor com a aplicação de uréia, em detrimento do nitrato de cálcio. A acidificação da rizosfera, segundo Moraghan \& Mascagni Jr. (1991), aumenta a eficiência na absorção de micronutrientes metálicos $\mathrm{Zn}, \mathrm{Mn}, \mathrm{Cu}$ e $\mathrm{Fe}$, cuja disponibilidade é influenciada pelo $\mathrm{pH}$.

Quanto às doses de Mn, também foi observado efeito apenas nos teores deste elemento no solo e nas folhas, ajustando-se equações de regressão quadráticas para estas três variáveis (Figura 1). Não houve interação significativa das fontes de $\mathrm{N}$ e das doses de $\mathrm{Mn}$ em nenhuma variável.

Os teores de Mn disponíveis no solo foram suficientes para uma produção adequada de biomassa, uma vez que não se verificou diferença significativa na produção de matéria seca de raízes e parte aérea em função da aplicação do Mn, assim como as doses de $\mathrm{Mn}$ não influenciaram o teor foliar de $\mathrm{N}$ em ambas as fontes de N (Figura 1). Verifica-se que os teores foliares médios de Mn nas plantas de trigo que não receberam aplicação de $\mathrm{Mn}$, apenas os teores disponíveis naturalmente no solo, foram de $60,75 \mathrm{mg} \mathrm{kg}^{-1}$. Esses teores foliares de Mn estão acima dos níveis considerados insuficientes para a cultura do trigo segundo Malavolta et al. (1997), justificando a ausência de incrementos de produção com o aumento da dose de Mn (Figura 1).

Verificou-se que quanto maior a dose de $\mathrm{Mn}$ aplicada, maiores foram os teores disponíveis deste micronutriente no solo e maior sua quantidade absorvida pela planta. O efeito das doses de Mn sobre os teores deste elemento nas folhas ajustou-se ao modelo quadrático. Maiores teores foliares de Mn com o aumento da dose desse nutriente também foram verificados na cultura do arroz, goiabeira e soja por Pereira et al. (2001), Salvador et al. (2003) e Oliveira Júnior et al. (2000), respectivamente.

\section{CONCLUSÕES}

1. A adição de $\left(\mathrm{NH}_{4}\right)_{2} \mathrm{SO}_{4}$ ao solo como fonte de $\mathrm{N}$ proporciona aumento da disponibilidade do Mn, que é acompanhada de aumento de sua absorção pela planta.

2. A severidade da mancha-marrom do trigo aumenta quando os teores de $\mathrm{Mn}$ no solo estão próximos aos relacionados à deficiência ou ao excesso desse micronutriente para as plantas.

3. $\mathrm{O}$ aumento das doses de $\mathrm{MnCl}_{2} \cdot 4 \mathrm{H}_{2} \mathrm{O}$ aplicadas ao solo como fonte de $\mathrm{Mn}$ tem como resposta o aumento do teor disponível desse elemento e o aumento de sua absorção por plantas.

\section{AGRADECIMENTOS}

Ao Prof. Fabrício Rodrigues de Ávila, pelo fornecimento das sementes de trigo e do inóculo, e à Vivian Missio, pelo auxílio no processo de inoculação das plantas, bem como ao Departamento de Fitopatologia da UFV, pelo empréstimo da câmara de inoculação.

\section{LITERATURA CITADA}

AGRIANUAL. Anuário da agricultura brasileira. São Paulo, FNP Consultoria e Comércio, 2008. 502p.

AGRIOS, G.M. Environmental effects on infection plant disease development. In: AGRIOS, G.M. Plant Pathotology. 3.ed. London, Academic Press, 1980. p.147155.

AGUILAR, M.A.G. Influência do manganês sobre aspectos bioquímicos e fisiológicos da tolerância do cacau (Theobroma cacao L.) à vassoura-de-bruxa (Crinipellis perniciosa (Stahel) Singer). Viçosa, MG, Universidade Federal de Viçosa, 1999. 181p. (Tese de Doutorado) 
BORKERT, C.M. Micronutrientes no solo: Manganês. In: FERREIRA, M.E. \& DA CRUZ, M.C., eds. Micronutrientes na agricultura. Piracicaba, Potafos/CNPq, 1993. p.173-190.

BROWN, P.H.; GRAHAM, R.D. \& NICHOLAS, D.J.D. The effects of manganese and nitrate supply on the level of phenolics and lignin in young wheat plants. Plant Soil, 81:437-440, 1984.

EL-JAOUAL, T. \& COX, D.A. Manganese toxicity in plants. J. Plant Nutr., 21:353-386, 1998.

FECHT-CHRISTOFFERS, M.M.; MAIER, P. \& HORST, W.J. Apoplastic peroxidase and ascorbate are involved in manganese toxicity and tolerance of Vigna unguiculata. Physiol. Plant., 117:237-244, 2003.

GOMEZ, K.A. \& GOMEZ, A.A. Statistical procedures for agricultural research. 2.ed. New York, John Wiley, 1984. $680 \mathrm{p}$.

HAMMERSCHMIDT, R. Phytoalexins: What have we learned after 60 years? Ann. Rev. Phytopathol., 37:285-306, 1999.

HE, Z.L.; ALVA, A.K.; CALVERT, D.V.; LI, Y.C. \& BANKS, D.J. Effects of nitrogen fertilization of grapefruit trees on soil acidification and nutrient availability in a Riviera fine sand. Plant Soil, 206:11-19, 1999.

HECKMAN, J.R.; CLARKE, B.B. \& MURPHY, J.A. Optimizing manganese fertilization for the suppression of take-all patch disease on creeping bentgrass. Crop Sci., 43:1395 1398, 2003.

HILL, W.J.; HECKMAN, J.R.; CLARKE, B.B. \& MURPHY, J.A. Take-all patch suppression in creeping bentgrass with manganese and copper. HortScience, 34:891-892, 1999.

HORSFALL, J.C. \& BARRATT, R.W. An improved grading system for measuring plant diseases. Phytopathology, 35:665 (Abstract), 1945.

HUBER, D.M. Introduction. In: ENGELHARD, A.W. Soilborne plant pathogens: Management of diseases with macroand microelements. St. Paul, APS Press, 1989. p.1-8.

HUBER, D.M. \& THOMPSON, L.A. Nitrogen and plant disease. In: DATNOFF, L.E.; ELMER, W.H. \& HUBER, D.M., eds. Mineral nutrition and plant disease. St Paul, The American Phytopathological Society Press, 2007. p.31-44.

HUBER, D.M. \& WATSON, R.D. Nitrogen form and plant disease. Ann. Rev. Phytopathol., 12:139-165, 1974.

HUSSAIN, G.; AL-JALOUD, A.A. \& KARIMULLA, S. Effect of treated effluent irrigation and nitrogen on yield and nitrogen use efficiency of wheat. Agric. Water Manag., 30:175-184, 1996.

KEINATH, A.P. \& LORIA, R. Management of common scab of potato with nutrients. In: ENGELHARD, A.W., ed. Soilborne plant pathogens: Management of diseases with macro and microelements. St. Paul, APS Press, 1989. p.152-166.

LEINA, M.; TAN, T.K. \& WONG, S.M. Resistance of Hibiscus esculentus L. and Vigna sinensis (L.) Endl. to Pseudocercospora and plant peroxidase activity in relation to infection. Ann. Appl. Biol., 129:197-206, 1996.
MALAVOLTA, E.; VITTI, G.C. \& OLIVEIRA, S.A. Avaliação do estado nutricional de plantas: Princípios e aplicações. Piracicaba, Potafos, 1997. 308p.

MARSCHNER, H. Mineral nutrition of higher plants. London, Academic, 1995. 889p.

MORAGHAN, J.T. \& MASCAGNI JR., H.J. Environmental and soil factors affecting micronutrient deficiencies and toxicities. In: MORTVEDT, J.J.; COX, F.R.; SHUMAN, L.M. \& WELCH, R.M., eds. Micronutrients in agriculture. 2.ed. Madison, SSSA, 1991. p.371-425.

MORGAN, P.W.; TAYLOR, D.M. \& JOHAM, J.M. Manipulation of AIA oxidase activity and auxin-deficiency synptoms in intact cotton plants with manganese nutrition. Physiol. Plant., 37:149-156, 1976.

NICHOLSON, R.L. \& HAMMERSCHMIDT, R. Phenolic compounds and their role in disease resistance. Ann. Rev. Phytopathol., 30:369-380, 1992.

OLIVEIRA JUNIOR, J.A.; MALAVOLTA, E. \& CABRAL, C.P. Efeitos do manganês sobre a soja cultivada em solo de Cerrado do Triângulo Mineiro. Pesq Agropec. Bras, 35:1629-1636, 2000.

PEREIRA, G.D.; BERTONI, J.C.; CARVALHO, J.G. \& MORAIS, A.R. Doses e modos de adubação com manganês e seus efeitos na produção da cultura do arroz. R. Bras. Ci. Solo, 25:625-633, 2001.

PERES, J.R.R. \& SUHET, A.R. Adubação nitrogenada no Planalto Central. In: REUNIÃO BRASILEIRA DE FERTILIDADE DO SOLO, 1984, Ilhéus. Anais... Ilhéus, CEPLAC/SBCS, 1986. p.221-242.

PILBEAM, D.J. \& KIRKBY, E.A. Some aspects of the utilization of nitrate and ammonium by plants. In: MENGEL K. \& PILBEAM D.J., eds. Nitrogen metabolism of plants. Oxford, Clarendon Press, 1992. p.55-70.

REIS, E.M.; COOK, R.J. \& MCNEAL, B.L. Effect of mineral nutrition on take-all of wheat. Phytopathology, 72:224$229,1982$.

RÖMHELD, V. PH changes in the rhizosphere of various crop plants in relation to the supply of plant nutrients. Potash Rev., 12:1-12, 1986.

SALVADOR, J.O.; MOREIRA, A.; MALAVOLTA, E. \& CABRAL, C.P. Influência do boro e do manganês no crescimento e na composição mineral de mudas de goiabeira. Ci. Agrotec., 27:325-331, 2003.

SILVA, J.T.A.; BORGES, A.L.; CARVALHO, J.G. \& DAMASCENO, J.E.A. Adubação com potássio e nitrogênio em três ciclos de produção da bananeira cv. Prata-anã. R. Bras. Frutic., 25:152-155, 2003.

SMILEY, R.W. \& COOK, R.J. Relationship between take-all of wheat and rhizosphere $\mathrm{pH}$ in soils fertilized with ammonium vs. nitrate-nitrogen. Phytopathology, 63:882889,1973

THOMPSON, I.A. \& HUBER, D.M. Manganese and plant disease. In: DATNOFF, L.E.; ELMER, W.H. \& HUBER, D.M., eds. Mineral nutrition and plant disease. St Paul, The APS Press, 2007. p.139-153. 
WISSEMEIER, A.H. \& HORST, W.J. Effect of light intensity on manganese toxicity symptoms and callose formation in cowpea (Vigna unguiculata (L.) Walp.). Plant Soil, 143:299-309, 1992.

ZANÃO JÚNIOR, L.; LANA, R.M.Q. \& SÁ, K.A. Parcelamento de fontes de adubação nitrogenada na produção de couveda-malásia. Hortic. Bras., 23:965-969, 2005.
ZANÃO JÚNIOR, L.A. Resistência do arroz à mancha-parda mediada por silício e manganês. Viçosa, MG, Universidade Federal de Viçosa, 2007. 124p. (Tese de Mestrado)

ZANÃO JÚNIOR, L.A.; ÁVILA, F.R.; FONTES, R.L.F.; KORNDÖRFER, G.H. \& NEVES, J.C.L. Rice resistance to brown spot mediated by silicon and its interaction whit manganese. J. Phytopathol., 157:73-78, 2009. 